\title{
A congenital malformation of the systemic heart complex in Sepia officinalis L. (Cephalopoda)
}

\author{
R. Schipp ${ }^{1 *}$, S. von Boletzky ${ }^{2}$, P. Jakobs ${ }^{1}$ \& P. J. Labourg ${ }^{3}$ \\ ${ }^{1}$ Institut für Allgemeine und Spezielle Zoologie, Justus-Liebig-Universität; \\ D-35390 Giessen, Germany \\ ${ }^{2}$ Observatoire Océanologique de Banyuls; F-66650 Banyuls-sur-Mer, France \\ ${ }^{3}$ Laboratoire d'Océanographie Biologique; F-33120 Arcachon, France
}

\begin{abstract}
In semi-adult Sepia officinalis L. (Cephalopoda) from the Bay of Arcachon (France) a congenital malformation of the systemic heart is described by macro- and microscopical methods. It concerns an atypical doubling of the site of insertion at the cephalic aorta at the apical ventricle. Its comparison with the paired anlagen of the systemic heart complex in normal embryogenesis and the central circulatory system of Nautilus gives rise to interpret it as a form of atavism. The possible causal role of mutagenic antifoulings is discussed.
\end{abstract}

\section{INTRODUCTION}

During our studies on the circulatory system of the cuttlefish Sepia officinalis L. in autumn of 1989 and 1996 a great number of animals with obvious malformations in the systemic heart complex were found. These were atypical doublings of the transition area of the apical ventricle to the cephalic aorta that are described and analysed in the present study by macroscopical, cytological and physiological methods. A comparison of these structures with early stages of the normal embryogenesis of the systemic heart complex on the one hand and with similar malformations in other marine molluscs on the other, revealed phylogenetical and ecotoxicological aspects of interest as well as possibilities of a causal interpretation (Naef, 1909, 1910; v. Boletzky, 1968; Alzieu et al., 1986; Bryan \& Gibbs, 1991; Bauer et al., 1995).

\section{MATERIALS AND METHODS}

The animals were caught in September/November 1989 and 1996 in submarine Zostera- and Posidonia sods - the so-called "herbier" - near the "Cap Ferrêt" of the Bay of Arcachon. For their number, age and sex, see Table 1. They were kept in circulated and aerated seawater tanks and fed with small fish (particularly Atherina) for 1-2 weeks before preparation. For the preparation the animals were anaesthetized in $1.5 \%$ etha-

\footnotetext{
- Addressee for correspondence and reprint requests: Professor Dr. R. Schipp, Stephanstr. 24, D-35390 Giessen; FAX: Germany 641/99-35609
} 
Table 1. Sepia officinalis L. with malformations of the systemic heart complex from the Bay of Arcachon (France) in 1989 and 1996

\begin{tabular}{|c|c|c|c|c|c|c|}
\hline & $\begin{array}{l}\text { Animal } \\
\text { No. }\end{array}$ & $\begin{array}{l}\text { Mantle length } \\
\text { (cm) }\end{array}$ & $\begin{array}{l}\text { Body weight } \\
\text { (g) }\end{array}$ & Sex & $\begin{array}{l}\text { Heart frequency } \\
\left(\mathrm{F} /{ }^{\prime}\right) \text { in situ }\end{array}$ & $\begin{array}{c}\text { Date of } \\
\text { preparation }\end{array}$ \\
\hline \multirow{18}{*}{$\stackrel{\mathscr{D}}{g}$} & 17 & 9.0 & 75 & $\mathrm{~m}$ & 61 & 26. 9.89 \\
\hline & 19 & 9.5 & 90 & $\mathrm{~m}$ & 70 & 26. 9.89 \\
\hline & 21 & 9.0 & 85 & f & 63 & 27. 9.89 \\
\hline & 22 & 12.0 & 180 & $\mathrm{~m}$ & 66 & 27. 9.89 \\
\hline & 28 & 12.0 & 200 & $\mathrm{~m}$ & 60 & 29. 9.89 \\
\hline & 42 & 9.5 & 95 & $\mathrm{~m}$ & 56 & 4. 10.89 \\
\hline & 43 & 11.0 & 140 & $\mathrm{~m}$ & - & 4. 10.89 \\
\hline & 45 & 10.5 & 130 & $\mathrm{f}$ & 52 & 5. 10.89 \\
\hline & 46 & 12.0 & 170 & - & 44 & 5. 10.89 \\
\hline & 48 & 11.5 & 210 & f & 60 & 5. 10.89 \\
\hline & 52 & 11.0 & 150 & $\mathrm{~m}$ & 12 & 7. 10.89 \\
\hline & 53 & 9.5 & 100 & $\mathrm{~m}$ & 59 & 7. 10.89 \\
\hline & 56 & 12.5 & 190 & $\mathrm{~m}$ & 54 & 10. 10.89 \\
\hline & 85 & 11.0 & 130 & $\mathrm{~m}$ & 62 & 23. 10.89 \\
\hline & 123 & 13.0 & 165 & $\mathrm{~m}$ & - & 24. 10.89 \\
\hline & 128 & 10.0 & 125 & $\mathrm{~m}$ & - & 25. 10.89 \\
\hline & 129 & 11.5 & 140 & $\mathrm{f}$ & - & 15. 10.89 \\
\hline & 1.30 & 13.0 & 200 & f & - & 26. 10.89 \\
\hline \multirow{4}{*}{$\stackrel{\mathscr{g}}{g}$} & 1 & 9.0 & 75 & f & - & 4. 10.96 \\
\hline & 7 & 11.0 & 150 & $\mathrm{~m}$ & - & 10.10 .96 \\
\hline & 15 & 8.0 & 60 & $\mathrm{~m}$ & - & 17.10 .96 \\
\hline & 22 & 10.5 & 132 & $\mathrm{~m}$ & - & 23.10 .96 \\
\hline
\end{tabular}

nol/seawater. After sectioning of the malformed systemic heart complexes, these were documented in situ and in vitro by macrophotography and drawings.

Some preparations were fixed in Bouin's solution for paraffin series-sections $(7-10 \mu \mathrm{m})$ that were stained by Masson's trichrome-, PAS-, and Bodian's nerve colouration. Some others served for physio-pharmacological tests by which the reactivity and the luminal flow of the malformed systemic heart complex was examined applying the method of anterograde perfusion via both auricles and the cannulated cephalic aorta with filtered aerated seawater $(0.17 \%$ glucose; $\mathrm{pH} 8.2)$ under a preload-/afterload pressure of 50/20 $\mathrm{mm}$ $\mathrm{H}_{2} \mathrm{O}\left(1 \mathrm{~mm} \mathrm{H}_{2} \mathrm{O}=9.81 \mathrm{~Pa}\right)$. The actogram of the isolated heart preparations was recorded by means of a pressure transducer (HSE W101) connected with the output cannula that was tied to the proximal cephalic aorta. An HSE-300 amplifier and Watanabe Mark V-recorder were used (for further methodological details, see Jakobs, 1991).

\section{RESULTS}

\section{Number and frequency of cases}

Of 130 preparations made of Sepia officinalis L. in 1989, 18 animals, i.e. $13.9 \%$, showed the malformation; $27.7 \%$ of them were females, $72.2 \%$ males. In 1996, 4 of 46 preparations showed the malformation. Their body weight ranged from 75 to $210 \mathrm{~g}$, their 
mantle length from 9 to $13 \mathrm{~cm}$ (Table 1). During the period from 1983 to 1988 not one of the 530 animals caught in the Bay of Arcachon showed any malformation of this kind. For the period from 1990 to 1995, no observations are available.

\section{Macromorphological aspects}

The malformations consisted of a trunk- or cord-like structure that in most of the cases originated from a cone-like evagination on the left cranio-apical area of the heart ventricle and joined the atypical elongated right apical part of the ventricle on the inner side just below the root of the aortic valve (Figs $1 \mathrm{a} / \mathrm{d}, 2 \mathrm{a} / \mathrm{b}$ ); more rarely it joined the root of the right ventricle dome as a short atypical trunk (Fig. 1b). In one case (animal No. 46/89) the structure originated from the dorsal area of the left ventricle part surrounding the stomach as a very small, elongated cord $(\varnothing 1.5-2 \mathrm{~mm})$ that joined the cephalic aorta just above the aortic valve (Fig. 1c, 3). Further anomalies that were obvious macroscopically concerned the right auricle and the origin of the A. renalis and A. genitalis that in some cases had been shifted by $\pm 90^{\circ}$ into a more ventral position (Fig. $2 \mathrm{~b}$ ) as well as the pancreatic appendages which had been shifted from the median position to the left side. Other organs like the genital tract showed no obvious malformations. In one case (animal No. 22/96) the A. genitalis ended within the gastral-arterial complex, and an atypical A. genitalis originating in this complex formed an atypical U-shaped loop running around the trunk-like malformation caudally to the testis.

\section{Physiological observations}

The in-situ observations in anaesthetized animals suggested that the function of the malformed hearts did not seem to be distinctly impaired. The beat frequency ( $F$ : 55 $\pm 15 / \mathrm{min}$ ) showed a similar range to that of normal hearts of animals of this age and mantle length ( $\mathrm{F}: 52 \pm 14 / \mathrm{min}$ ). In many cases contractions of the atypical trunk of the ventricle could be observed. When these were very small and extremely elongated (animal 46/89; Fig. 1c) no spontaneous contractility was detectable, but mechanical excitations, i.e. longitudinal expansions, could often induce transient periods of rhythmical contractions in the longitudinal axis of such trunks (F: 25-41/min).

Isolated preparations perfused constantly via both auricles (PLP: $50 \mathrm{~mm} \mathrm{H}_{2} \mathrm{O}_{i}$ ALP: $20 \mathrm{~mm} \mathrm{H}_{2} \mathrm{O}$ ) revealed that in the most malformed organs the atypical ventricular trunk could be streamed through; i.e. in situ it functioned as a contractile by-pass to the normal right-side fluid shunt directed towards the cephalic aorta, as could also be demonstrated by using Evans-blue as a marker for the fluid stream. In preparations of hearts with a small elongated trunk as mentioned above (animal 46/89; Fig. 1c; 3), no fluid circulation was noted, thus its lumen seemed to be closed.

The comparison of the actograms of malformed isolated hearts with those of normal organs revealed that - according to the in-situ observations - the isolated organs also showed a normal frequency but an impaired rhythmicity, i.e. the amplitude of the contractions was not constant but changed arhythmically by up to $100 \%$ of the basal value (Fig. 4; animal 28/89).

Trunks isolated from the heart and perfused under physiological pre- and afterload pressure also showed contractions of a changing rhythm (F: 66-86/min; animal 45/89). 

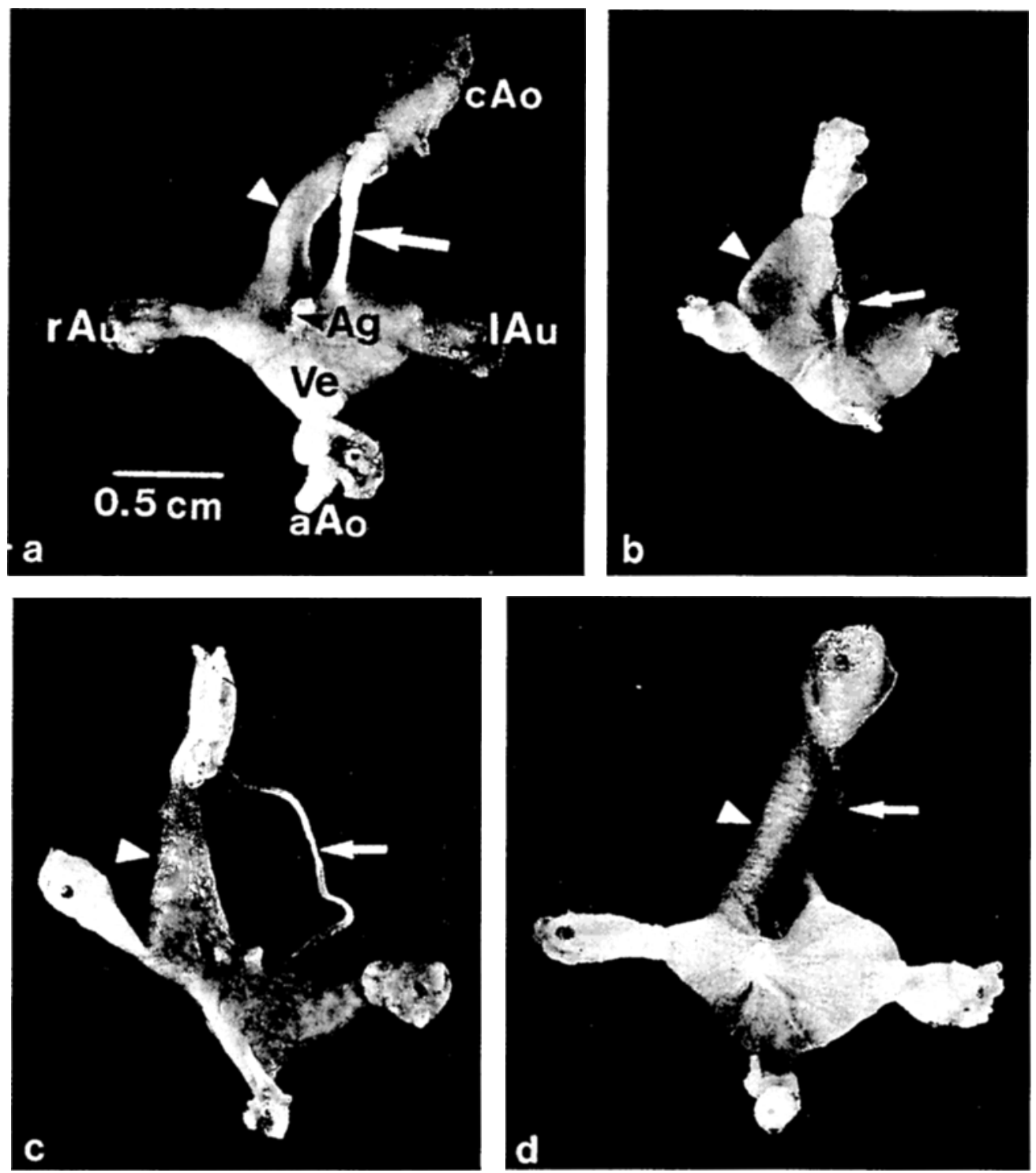

Fig. 1. Macroscopical preparations of malformed systemic hearts of Sepia officinalis in ventral view (a-d); abdominal aorta (aAo), cephalic aorta (cAo), genital artery (Ag), left and right auricle (lAu, rAu), ventricle (Ve), normal right apical ventricle dome (arrow-heads), atypical left trunk (arrow); animal - no.: 28/89 (a), 53/89 (b), $46 / 89$ (c), $42 / 89$ (d) 

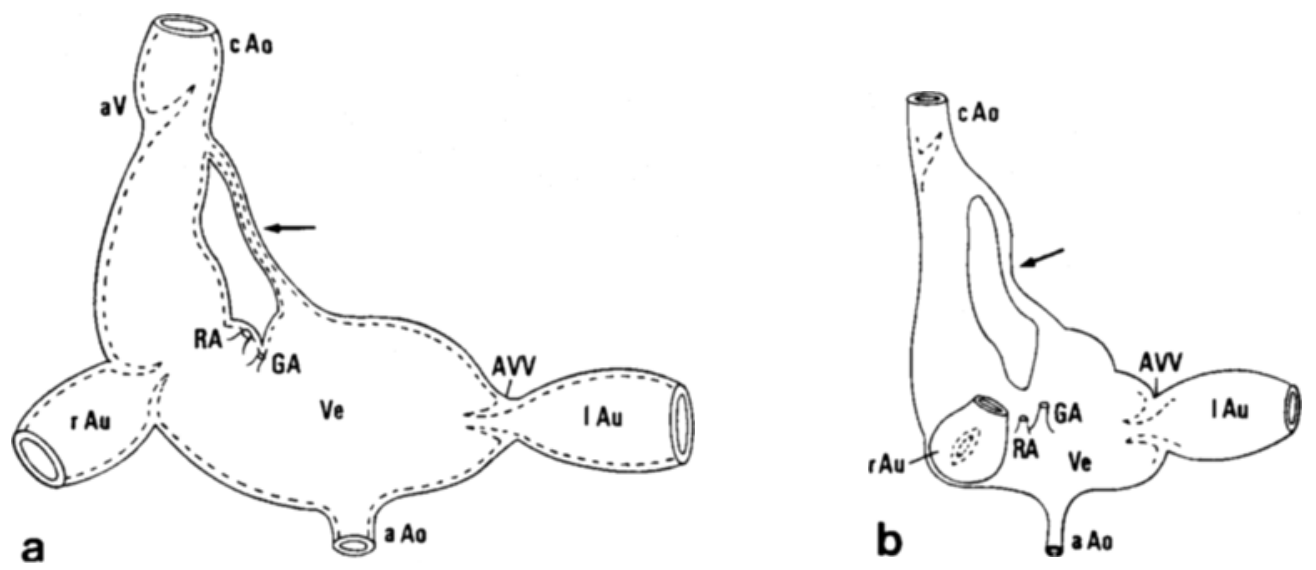

Fig. 2. Diagrams of malformed systemic hearts of Sepia officinalis in ventral view (animal 42/89:a, 28/89:b); atypical left trunk (arrow), aortic valve (aV), atrio-ventricular valve (AVV), renal artery (RA); further explanations as in Fig. 1

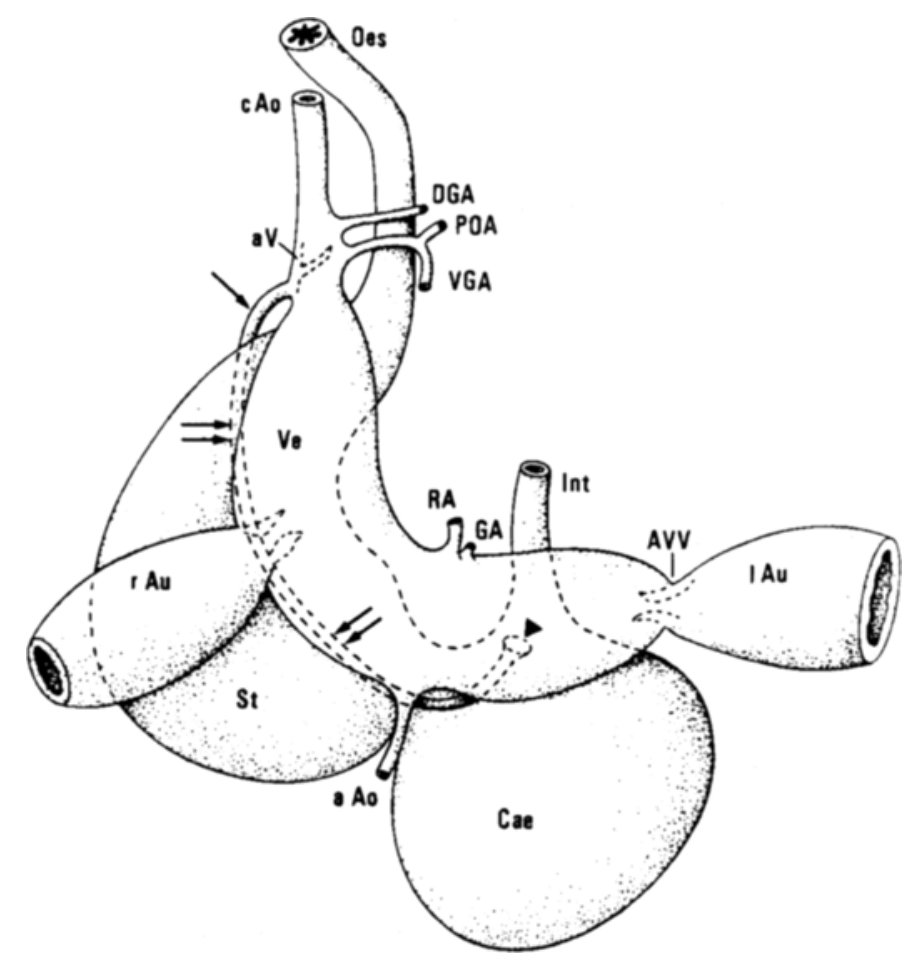

Fig. 3. Diagram of a malformed systemic heart of Sepia officinalis in ventral view (animal 46/89; comp. Fig. 1c); the atypical left trunk (arrows) forms a loop which encloses parts of the digestive tract; opening of the trunk into the ventricle (arrow-head), caecum (Cae), dorsal and ventral gastric artery (DGA/VGA), intestine (Int), oesophagus (Oes), posterior oesophagial artery (POA), stomach (St); further explanations as in Figs 1 and 2 

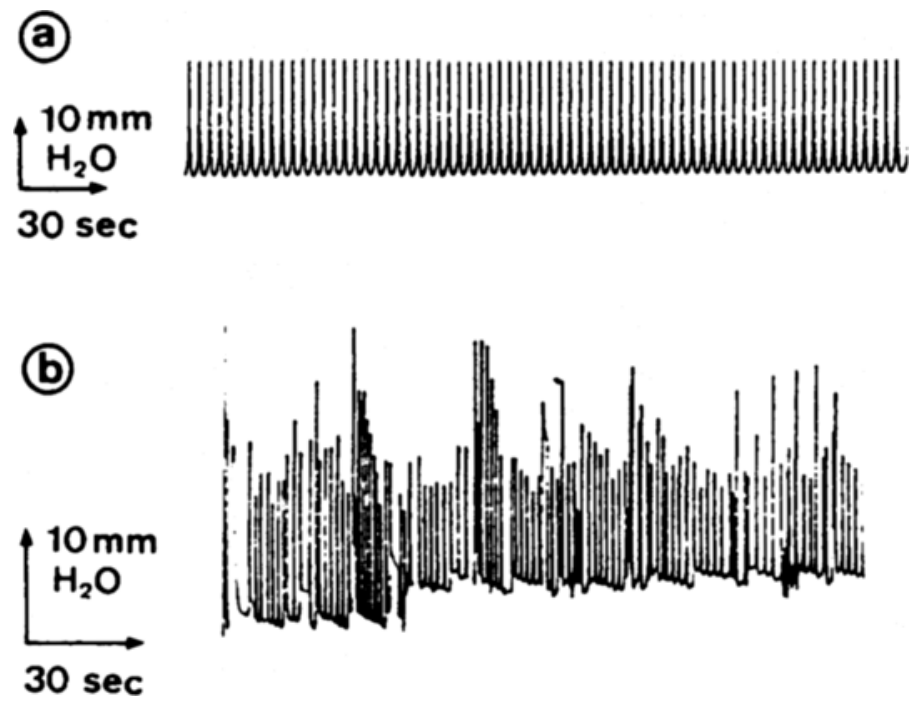

Fig. 4. Actogram of an isolated normal (a) and malformed (b) systemic heart of Sepia officinalis anterogradly perfused via both auricles by seawater-glucose solution

\section{Histological analysis}

According to the histological investigations the atypical trunk of the left apical ventricle showed two fundamentally different forms in the structure of the wall:

(a) When the trunk had an open lumen that communicated directly with that of the central and right apical lumen of the ventricle (Fig. 5c), the wall had a "cardio-like" 3-layered structure:

1. An "endocard" with a small incomplete endothelium bordering on an irregular lumen and connected with a small layer of connective tissue (Fig. $5 \mathrm{a} / \mathrm{b}$ ).

2. An extended spongy "myocard" with an inner longitudinal and an external circular muscle layer which are innervated by scattered nerve fibres - branches of the N. cardiacus - and show enlarged intercellular spaces and lacunae (Fig. 5b).

3. An "epicard" consisting of a columnar epithelium bordering on the pericardial coelom closely connected with a small subepithelial layer of collagenous fibres (Fig. $5 \mathrm{a} / \mathrm{b}$ ).

(b) In cases where the trunk did not show a thorough lumen, i.e. it had only a partial distal lumen which communicated only distally with the right apical ventricle lumen near the origin of the cephalic aorta, it showed a vessel-like 3-layered wall structure:

1. A "T. intima" with a very small incomplete endothelium closely connected with a large amorphous layer that is nearly free of cells and reacted PAS-positive that could be seen as an atypical basal lamina (Fig. 6d).

2. A "T. media" with circularly and longitudinally arranged muscle cells and collagenous fibres (Fig. 6d).

3. An extended " $T$. adventitia" consisting of a collagenous network with singular muscle cells, small capillary-like blood vessels and numerous nerve fibres (Fig. 6d). It is peripherally bordered by the columnar coelom epithelium which often shows an irregular fuzz-like structure. 

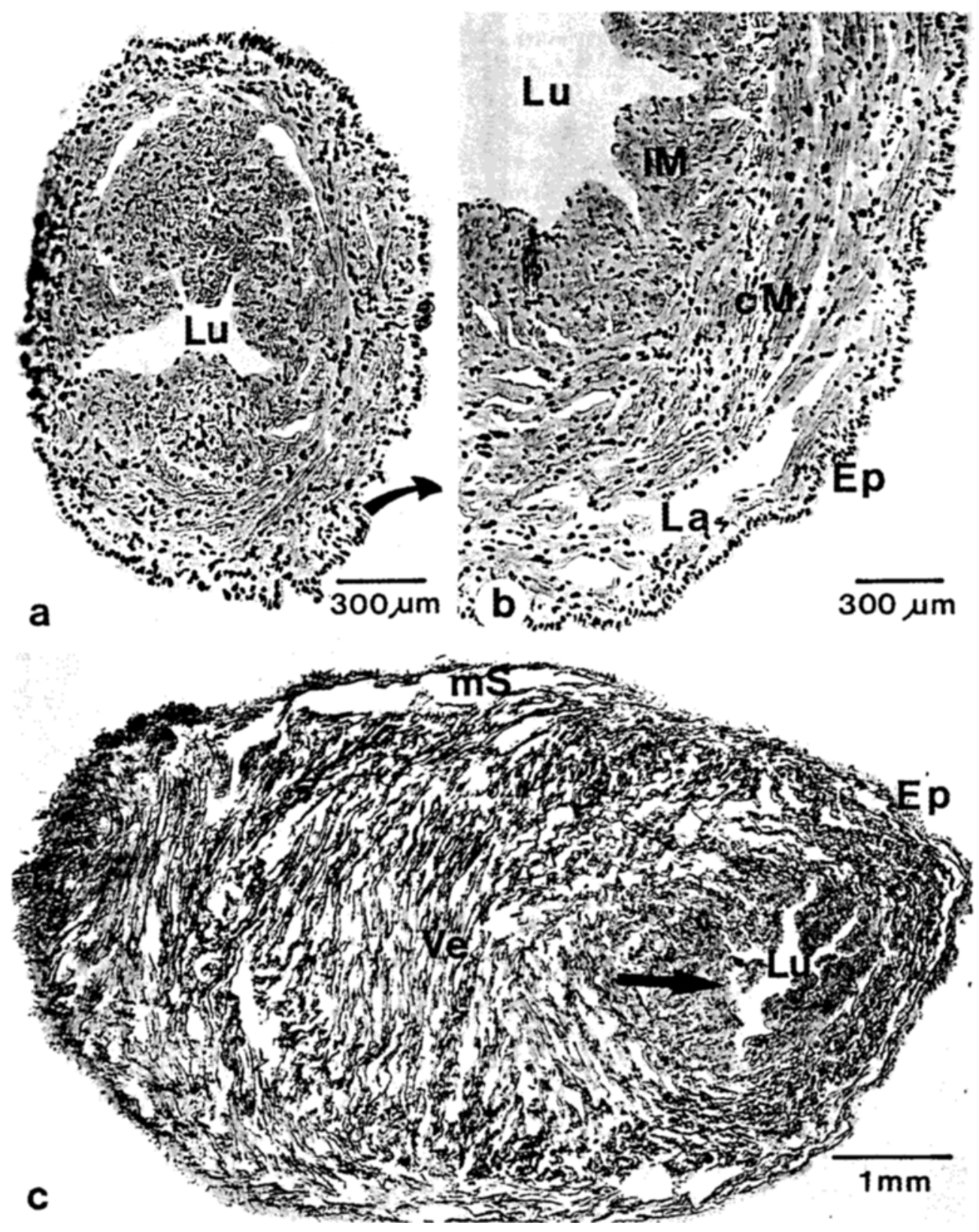

Fig. 5. Sepia officinalis. Cross section of the mid-area of the atypical trunk of animal: 28/89 (a); section of the trunk wall in higher magnification - "heart wall-like aspect" - (b); insertion area of the trunk at the heart ventricle tangentially sectioned (c, arrow); epithelium (Ep), blood lacunae (La), lumen (Lu), longitudinal and circular muscle fibres $(\mathrm{lM} / \mathrm{cM})$, marginal sinus $(\mathrm{mS})$ of the heart ventricle (Ve); colouration after Bodian $(\mathrm{a} / \mathrm{b})$ and Masson (c) 


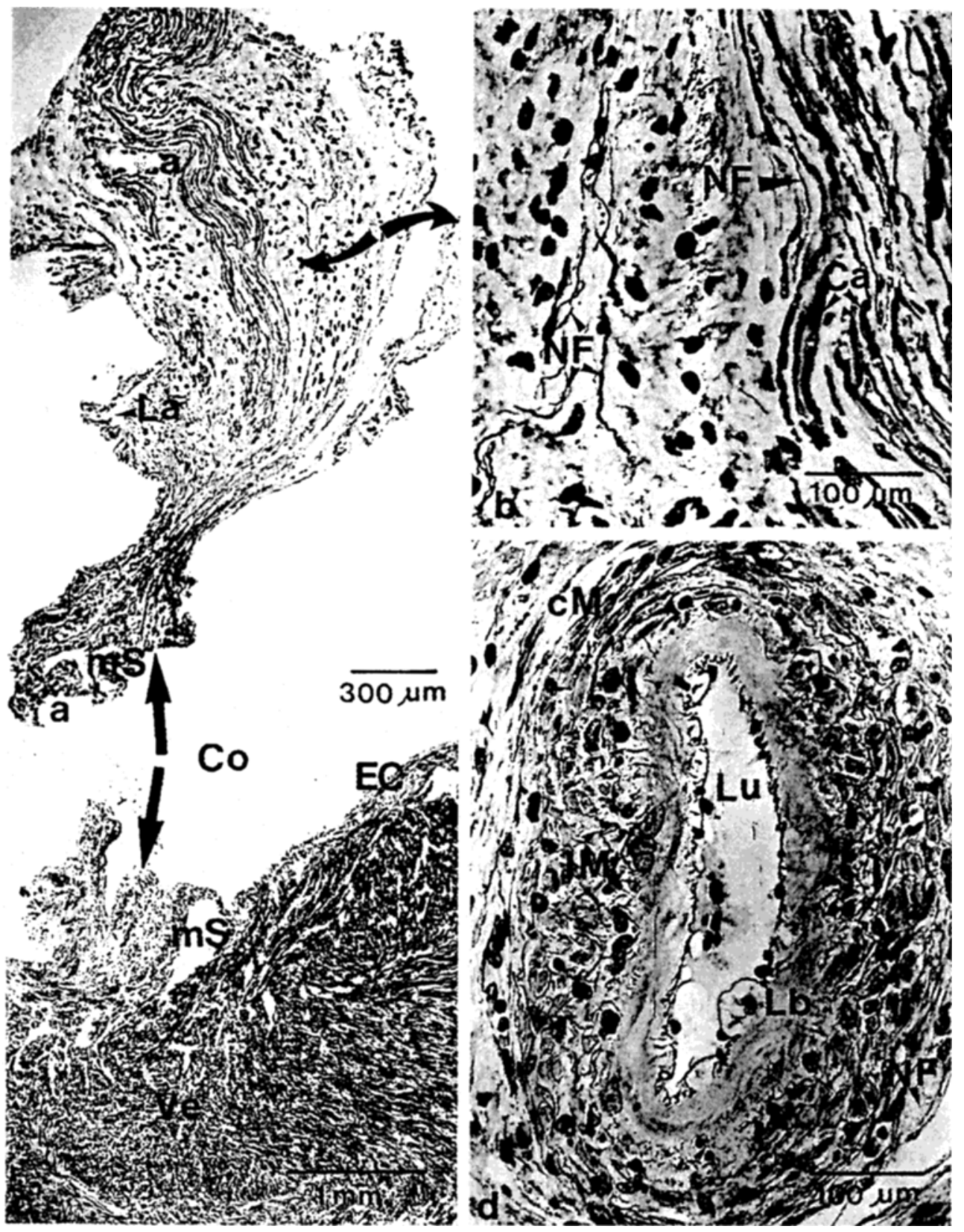

Fig. 6. Sepia officinalis. Longitudinal section of the atypical trunk of animal: 19/89 without an open lumen nearby the heart ventricle (a); partial section of Fig. $a$ in higher magnification (b); insertion area of this trunk (arrow) at the peripheral ventricle wall (c); cross section of the distal area of this trunk with an open lumen - "vessel-like aspect" - (d); capillaries (Ca), coelom (Co), epicard (EC), atypical lamina basalis (Lb), nerve fibres (NF); further abbreviations as in Fig. 5; colouration after Bodian $(\mathrm{a} / \mathrm{b})$ and Masson $(\mathrm{c} / \mathrm{d})$ 
In the area near the site of origin at the left apical ventricle, the lumen-less part of this kind of trunk consists of longitudinally arranged collagenous fibres, fibrocytes and muscle cells. Between these there are bundles of nerves, blood lacunae and capillaries running parallel to the trunk axis (Fig. $6 \mathrm{a} / \mathrm{b}$ ). The origin of these structures could be localized within the epicard of the ventricle (Fig. $6 \mathrm{a} / \mathrm{C}$ ). There is structural evidence that these blood lacunae and capillaries linked the subepicardial marginal sinus of the heart ventricle on the one side and the lumen of the distal trunk on the other and that in vivo an aneurysmatic circulation of hemolymph had been established.

\section{DISCUSSION}

Considering the nutritional condition and the physiological state of the animals as well as the macro- and microscopical aspects of the congenital heart anomaly found in a high percentage of Sepia officinalis caught in the Bay of Arcachon in the autumn of 1989 and 1996, it can be concluded that the anomaly impaired the hemodynamics of the central circulatory system, but that it was not life-threatening to the animals. Furthermore, there were no signs of impairment as far as the reproductive ability of the animals was concerned.

Despite a certain variability in the body size, there is no doubt that all malformed animals prepared in 1989 stemmed from the same period of reproduction. The fact that in the years before 1989 in a representative number of 530 further preparations of $S$. officinalis from this area of the Bay of Arcachon a comparable malformation could never be detected, is suggestive of a singular mutagenic event. Considering the high reproductive rate of $S$. officinalis - one female is capable of spawning more than 3000 eggs during one spawning period of some months (v. Boletzky, $1987 \mathrm{~b} ; 1988$ ) - it cannot be excluded that all malformed animals of that year originated from one maternal animal.

The question concerning the possible heredity of the congenital malformation, i.e. whether the malformations found in preparations of 1996 have to be reduced to mutations of animals of earlier spawning periods (1989?) or originate in more recent mutagenic events of the spawning period of 1996, cannot be answered.

The mutation seems to be restricted to the mesodermal anlage of the systemic heart complex only. The physiological and histological analysis suggests that in most cases the trunk-like doubling represents an additional left apical dome of the ventricle with a functioning typical heart wall and lumen (Kling \& Schipp, 1987). In other cases the doubling had an incomplete lumen and showed more the structural characteristics of an artery-like vessel, i.e. it seemed to represent an additional basal trunk of the cephalic aorta.

The malformation described here can be interpreted as the full expression of a morphogenetic program that is normally inhibited unilaterally. Indeed Naef (1909) showed that the normal embryonic development of Loligo vulgaris reflects the establishment of an originally paired structure during early stages of systemic heart formation, and that the bilateral symmetry of this complex is only given up by the subsequent regression of the left-hand root of the cephalic aorta. Based on his observations, he proposed a coleoid morphotype with a primitive systemic heart structure characterized by two antero-lateral issues leading to an unpaired cephalic aorta (Fig. 7). Although the bilateral symmetry is not perfect in the malformed heart complexes described here, the additional canal ob- 

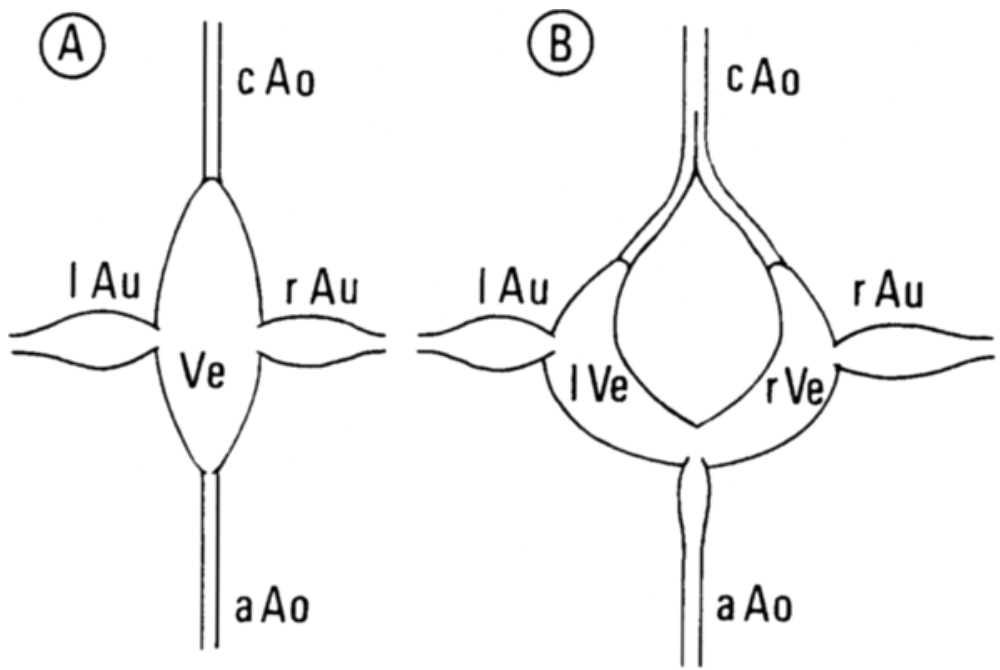

Fig. 7. Sepia officinalis. Schemes of a normal systemic coleoid heart (A) and of a hypothetical ancestral cephalopod with a paired basal trunk of the cephalic aorta (B); abbreviations as in Fig. 1-3; after Naef (1909)

served may be reasonably interpreted as an atavism, i.e. as an expression of the supposedly primitive morphogenetic program envisaged by Naef.

The rearrangement of the cephalic vein branches in Octopus (v. Boletzky, 1968, 1987 a) is a different example of such an atavistic expression: here a clearly primitive, bilaterally symmetrical pair of venous branches undergoes a morphogenetic modification that leads to a definitive asymmetric pattern, as postulated already by Naef (1910). Compared to this relatively late rearrangement, which starts from a fully expressed, primitive morphotype, the normal morphogenesis of the systemic heart appears as the result of very early suppression of the left root of the cephalic aorta.

Recently, a particularly interesting example of double formation was observed in a male Illex coindetii, which showed two functional gonoducts (Bello, 1993). Here the atavistic nature of the paired organs is most obvious, because female Illex always have two functional gonoducts. This indeed suggests an ancestral layout with paired gonoducts, from which unilateral gonoduct expression in males and in the females of various forms is derived by inhibition of the organogenetic expression on the opposite side.

The three examples considered above highlight the similarity between normally and anormally expressed ancestral programs in morphogenesis. These expressions are very different from the classical examples of "double monsters", most of which are not viable (cf. Ranzi, 1957). Yet the underlying mechanisms of genetic control in morphogenesis could be the same (Alberch, 1980, 1989). Experimental approaches allowing to elucidate the mechanism of atavistic heart development should therefore yield more than just a detailed picture of the processes leading to this malformation.

On the basis of the present state of knowledge, as far as possible causes of the mutation are concerned, it should be noted that in different areas of the Bay of Arcachon this also applies to the area around "La Vigne" in which the malformed cuttlefish were 
caught - between 1982 and 1985 a high tributyltin (TBT) induced tin contamination was registered. It has been seen to be responsible in that area for oyster shell anomalies (Alzieu et al., 1986) as well as toxic effects on mollusc larvae (His \& Robert, 1985). The teratogenic effect of the antifouling compound TBT on other marine molluscs is documented and has been proved experimentally; in prosobranchia (Nucella lapillus, Littorina littorea, Trivia arctica) it induced obvious malformations of the genital tract - termed imposex - that are characterised by a superimposition of male sex organs (penis and/or vas deferens) on females (Bryan et al., 1986; Oehlmann et al., 1992; Stroben et al., 1992; Bauer et al., 1995).

At present it cannot be excluded that there is also a causal relationship between the heart malformations of Sepia officinalis presented here and the high tin contamination registered in the Bay of Arcachon during the eighties.

Acknowledgements. This study is dedicated to Prof. R. Baessler, Fulda, in honour of his 70th birthday. The authors want to thank Prof. C. Cazaux, Prof. M. Caumette, Laboratoire d'Océanographie Biologique, Arcachon, who provided the facilities for work in their laboratories, and H. Côté, B. Fronk, A. Hudel, M. Kopsch, A. Polenz, H. Schmidt for their valuable technical assistance. The studies were supported by grants of the "Deutsche Forschungsgemeinschaft".

\section{LITERATURE CITED}

Alberch, P., 1980. Ontogenesis and morphological diversification. - Am. Zool. 20, 653-667.

Alberch, P., 1989. The logic of monsters: evidence for internal constraint in development and evolution. - Geobios (mém. spéc.) 12, 21-57.

Alzieu, C., Sanjuan, J., Deltreil, J. P. \& Borel, M., 1986. Tin contamination in Arcachon Bay: effects on oyster shell anomalies. - Mar. Pollut. Bull. 11, 494-498.

Bauer, B., Fioroni, P., Oehlmann, J., Schulte-Oehlmann, U. \& Stroben, E., 1995. Intersex - tributyltin causes malformations of the pallial oviduct with resulting reproductive failure in Littorina littorea. In: Twelfth International Malacological Congress. Ed. by A. Guerra, E. Rolán \& F. Rocha. CSIC, Vigo, 134-135.

Bello, G., 1993. Male specimen of Illex coindetii (Oegopsida, Ommastrephidae) with two functional gonoducts. - J. Cephalopod Biol. 2, 1-2.

Boletzky, S. von, 1968. Untersuchungen über die Organogenese des Kreislaufsystems von Octopus vulgaris Lam. - Revue suisse Zool. 75, 765-812.

Boletzky, S. von, 1987a. Ontogenetic and phylogenetic aspects of the cephalopod circulatory system. - Experientia 43, 478-483.

Boletzky, S. von, $1987 \mathrm{~b}$. Fecundity variation in relation to intermittent or chronic spawning in the cuttlefish, Sepia officinalis L. (Mollusca, Cephalopoda). - Bull. mar. Sci. 40, 382-387.

Boletzky, S. von, 1988. A new record of long-continued spawning in Sepia officinalis (Mollusca, Cephalopoda). - Rapp. P.-v. Réun. Commn. int. Explor. scient. Mer Méditerr. 31, 257.

Bryan, G. W. \& Gibbs, P. E., 1991. Impact of low concentrations of tributyltin (TBT) on marine organisms: a review. In: Metal ecotoxicology: concepts and applications. Ed. by M. C. Newman \& A. W. McIntosh. Lewis Publ., Ann Arbor, 323-361

Bryan, G. W., Gibbs, P. E., Hummerstone, L. G. \& Burt, G. R., 1986. The decline of the gastropod Nucella lapillus around south-west England; evidence for the effect of tributyltin from antifouling paints. - J. mar. biol. Ass. U.K. 66, 611-640.

His, E. \& Robert, R., 1985. Développement des véligères de Crassostrea gigas dans le bassin d'Arcachon. - Etudes sur les mortalités larvaires. - Revue Trav. Inst. Pêch.marit. 47, 63-68.

Jakobs, P., 1991. Effects of FMRFamide and some analogues on the isolated systemic heart of Sepia officinalis L. in orthograde perfusion. - I. Intern. Symposium on the cuttlefish Sepia, 1989. Centre Publ. Univ. Caen., Caen, 237-247.

Kling, G. \& Schipp, R., 1987. Comparative ultrastructural and cytochemical analysis of the cephalopod systemic heart and its innervation. - Experientia 43, 502-511. 
Naef, A., 1909. Die Organogenese des Coelomsystems und der zentralen Blutgefäße von Loligo. Jena. Z. Naturwiss. 45, 221-266.

Naef, A., 1910. Zur vergleichenden Anatomie und Entwicklungsgeschichte des Blutgefäßsystems der Cephalopoden. - Zool. Anz. 36, 316-329.

Oehlmann, J., Stroben, E. \& Fioroni, P., 1991. The morphological expression of imposex in Nucella lapillus (Linnaeus) (Gastropoda: Muricidae). - J. moll. Stud. 57, 375-390.

Ranzi, S., 1957. Early determination in development under normal and experimental conditions. In: The beginnings of embryonic development. Ed. by A. TYler, R. C. von Borstei \& C.B. Metz. Am. Ass. Adv. Sci., Washington, D. C., 48, 223-228.

Stroben, E., Brömmel, C., Oehlmann, J. \& Fioroni, P., 1992. The genital systems of Trivia arctica and T. monacha (Prosobranchia, Mesogastropoda) and tributyltin induced imposex. - Zool. Beitr. (N.F) $34,349-374$. 